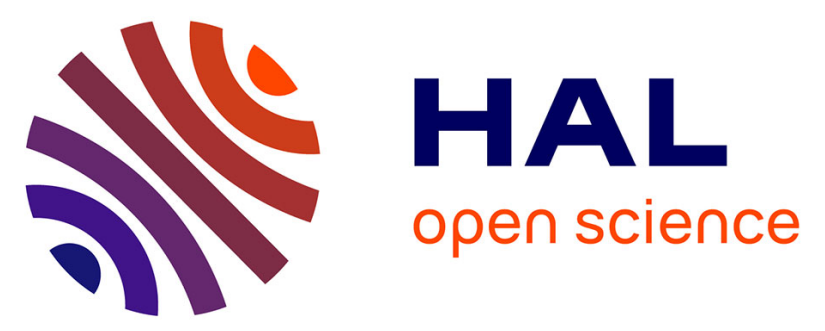

\title{
Evidence for the contribution of degenerate hydrogen atom transport to the persistence of sulfanyl radicals anchored to nanostructured hybrid materials
}

Francois Vibert, Emily Bloch, Michèle P Bertrand, Severine Queyroy, Stéphane Gastaldi, Eric Besson

\section{To cite this version:}

Francois Vibert, Emily Bloch, Michèle P Bertrand, Severine Queyroy, Stéphane Gastaldi, et al.. Evidence for the contribution of degenerate hydrogen atom transport to the persistence of sulfanyl radicals anchored to nanostructured hybrid materials. New Journal of Chemistry, 2017, 41 (14), pp.6678 - 6684. 10.1039/C7NJ00891K . hal-01784911

\section{HAL Id: hal-01784911 \\ https://hal-amu.archives-ouvertes.fr/hal-01784911}

Submitted on 3 May 2018

HAL is a multi-disciplinary open access archive for the deposit and dissemination of scientific research documents, whether they are published or not. The documents may come from teaching and research institutions in France or abroad, or from public or private research centers.
L'archive ouverte pluridisciplinaire HAL, est destinée au dépôt et à la diffusion de documents scientifiques de niveau recherche, publiés ou non, émanant des établissements d'enseignement et de recherche français ou étrangers, des laboratoires publics ou privés. 


\title{
Journal Name
}

\section{ARTICLE}

\section{Evidence for the Contribution of Degenerate Hydrogen Atom Transport to the Persistence of Sulfanyl Radicals Anchored to Nanostructured Hybrid Materials}

Received 00th January 20xx,
Accepted 00th January 20xx

DOI: $10.1039 / \times 0 \times x 00000 x$

\author{
François Vibert, ${ }^{a}$ Emily Bloch, ${ }^{\mathrm{b}}$ Michèle P. Bertrand, ${ }^{\mathrm{a}}$ Séverine Queyroy, ${ }^{* \mathrm{a}}$ Stéphane Gastaldi, ${ }^{\mathrm{a}}$ Eric \\ Besson* $*^{\mathrm{a}}$
}

\begin{abstract}
Nanostructured functionalized silicas were used as a platform to compare the behaviour of anchored arylsulfanyl radical depending on the nature of the precursor (diazene/thiol). The radicals generated from thiols exhibit higher half-lifetimes than the radicals issued from diazenes. The ability of thiols to maintain the sulfanyl radical density via degenerate hydrogen atom transfer is likely to account for this sharp difference.
\end{abstract}

\section{Introduction}

The continuous interest in persistent and stable radicals ${ }^{1}$ arises from their broad spectrum of applications, ranging from spectroscopy $\left(E P R,{ }^{2}{ }^{2} N^{3}\right)$ to the design of smart devices. ${ }^{4}$ The persistence and the stability of these families of radicals can originate either from steric effects, as exemplified by triarylmethyl radicals, or from electronic effects, as illustrated with the phenalenyl radical, but most often it results from a subtle interplay of both effects. ${ }^{5}$

Furthermore, it is known that the persistence of a radical can be improved by sorption onto materials ${ }^{6}$ such as zeolites, ${ }^{7}$ or by grafting onto a silica. ${ }^{8}$ In such situations, the increase of radical lifetimes has been rationalized in term of limited diffusion and/or interactions with the surface.

Progress in the synthesis of mesoporous silicas via the sol-gel process in the presence of structure-directing agents enables the preparation of organic-inorganic hybrid nanostructured materials. The organic moiety can be selectively located and regularly distributed on the pore surface of the silica with a sharp control of the loading. ${ }^{9}$ The multiscale control of the structure of mesoporous silicas was used to investigate the parameters responsible for the increase of the lifetime of transient radicals anchored to the material.

In previous studies, we have shown that the structure of the hybrid material played a key role in the improvement of the lifetimes of radicals anchored in the framework ${ }^{10}$ or on the pore $^{11}$ of mesoporous silicas. The presence of an organic monolayer on the pore surface was shown to be of crucial importance to disfavour the coupling reaction, i.e. the formation of disulfides, which is the main contributor to the

\footnotetext{
Aix Marseille Univ, CNRS, ICR, Marseille, France. E-mail : stephane.gastaldi@univamu.fr, eric.besson@univ-amu.fr.

${ }^{b .}$ Aix Marseille Univ, CNRS, MADIREL, Marseille, France.

Electronic Supplementary Information (ESI) available: [Characterizations for the organic compounds and the derived materials (NMR, TEM, SAXS, Nitrogen adsorption/desorption analysis, ATG), simulations, EPR decay curves]. See DOI: $10.1039 / x 0 x x 00000 x$
}

decay of the EPR signal in the case of arylsulfanyl radicals. ${ }^{11}$ In these materials, the arylsulfanyl half-lifetime $\left(t_{1 / 2}\right)$ is considerably improved, up to a $10^{9}$ factor compared to the reference value of $200 \mu$ s estimated by flash photolysis for phenylsulfanyl radical in solution. ${ }^{12}$ However, in systems as complex as hybrid materials, no simple rationale can be drawn to account for the increase of the radical lifetime because of the numerous parameters that are involved in the phenomenon. We found it important to evaluate the incidence of the nature of the organic functional groups in the neighbourhood on the radical persistence. In a first approach, the arylsulfanyl radicals were generated in the pore of the silica from the homolysis of a $\mathrm{S}-\mathrm{H}$ bond. Thus, the created radicals were surrounded by hydrogen atom donors. In order to decrease the reducing nature of the pore surface, a diazene was designed as an alternative precursor for the very same arylsulfanyl radicals. The comparative results are discussed in the following.

\section{Results and discussion}

A simple photolysis can trigger the fragmentation of the diazene group. The loss of dinitrogen leads to a pair of alkyl radicals. ${ }^{13}$ The $\beta$-sulfur carbon-centered radicals are well known to undergo a fast $\beta$-fragmentation ${ }^{14}$ releasing the sulfur-centered radicals (Scheme 1 ).

The dissymmetric diazene precursor 1 was prepared in two steps via the substitution of mesylate $\mathbf{5}$ with thiol $\mathbf{4}$ followed by the olefin hydrosilylation (Scheme 2). The dissymmetric diazene $\mathbf{5}$ was prepared from aminoester $\mathbf{9}$, via its conversion in bis-sulfonamide $\mathbf{8}$. The extrusion of sulfur dioxide led to diazene $\mathbf{7}$ which was subsequently converted into mesylate 4 . The triethoxysilane $\mathbf{1}$ was used to prepare mesostructured silicas $\mathbf{S B A}_{\mathbf{n}}-\mathbf{1}^{15}$ by direct synthesis, ${ }^{9}$ that is, the cocondensation of $\mathbf{1}$ and tetraethyl orthosilicate (TEOS) in the presence of $\mathrm{P} 123\left(\mathrm{PEO}_{20} \mathrm{PPO}_{70} \mathrm{PEO}_{20}\right)$ as structure directing agent. This process enabled the preparation of SBA-15 type of mesoporous silicas as illustrated by their surface areas, their 
pore diameters and pore volumes (Table 1 ). In both series $\mathbf{S B A}_{\mathbf{n}} \mathbf{- 1}$ and $\mathbf{S B A}_{\mathbf{n}}-\mathbf{2}$, as usually observed, the surface areas increased while the concentration in organic functions decreased. Concerning the pore diameter, the difference between the two materials was more pronounced. While pore diameters were quite regular for $\mathbf{S B A}_{\mathrm{n}} \mathbf{- 2}$, they notably increased for $\mathbf{S B A}_{\mathbf{n}} \mathbf{- 1}$ for the lower loadings what might be related to the steric hindrance of the radical precursors. The hybrid silica $\mathbf{S B A}_{47}-\mathbf{1}$ was passivated upon reaction with $\mathrm{ClSiMe}_{3}$. The characterization of all materials demonstrated that the diazene moiety was stable to the sol-gel process conditions.

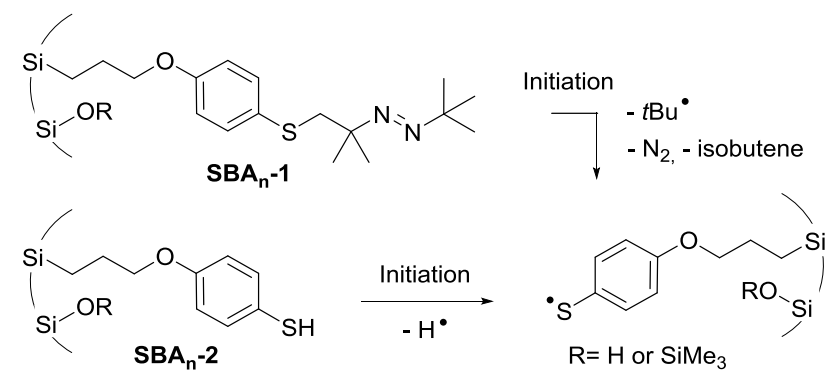

Scheme 1 Radical generation

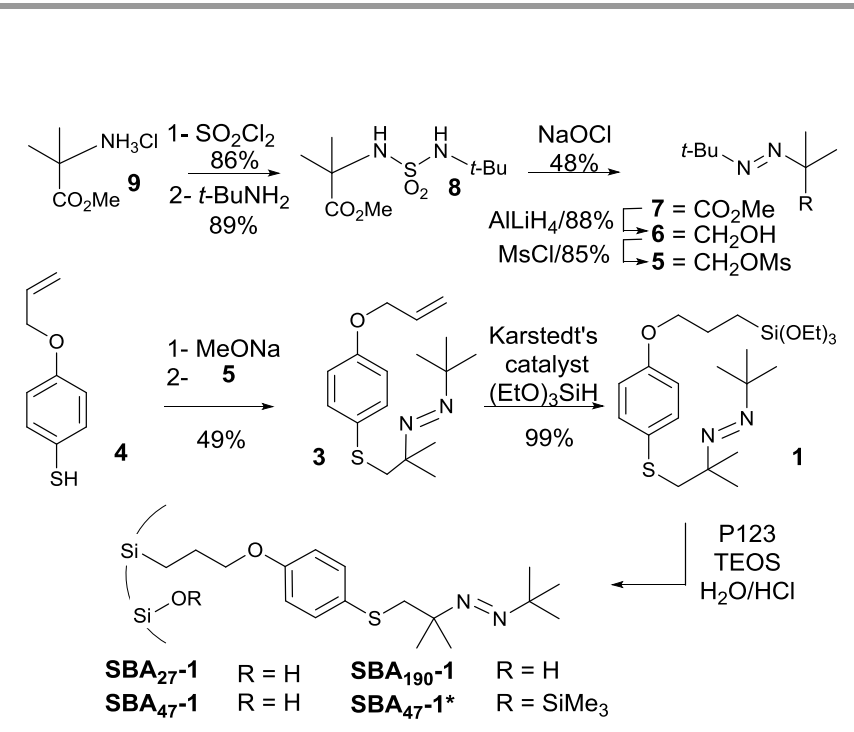

Scheme 2 Diazene precursor synthesis

The behaviour of the arylsulfanyl radicals generated from the photolysis of these precursors was investigated by EPR. In a typical procedure, the functionalized material was degassed $\left(10^{-5} \mathrm{mbar}\right)$ in a $4 \mathrm{~mm}$ quartz-glass tube and arylsulfanyl radicals were generated via the light-induced decomposition of the diazene inside the spectrometer cavity (xenon lamp $(200-800 \mathrm{~nm}))$. An anisotropic signal, resulting from the immobilization of the radicals, was recorded at room temperature after irradiation whatever the functionalized silica. The EPR parameters of these signals were in agreement with the formation of arylsulfanyl radicals ${ }^{10,11,16}$ for which the $g$ tensor is axisymmetrical and the spin density is localized on the sulfur atom. ${ }^{17} \mathrm{~A}$ representative spectrum is shown in Fig. 1 a.

\begin{tabular}{|c|c|c|c|c|}
\hline & Silica & Surface area ${ }^{a}$ & Pore diameter ${ }^{b}$ & Pore volume $^{c}$ \\
\hline $\mathrm{a}$ & $\mathrm{SBA}_{27}-1$ & 451 & 5.1 & 0.77 \\
\hline b & $\mathrm{SBA}_{47}-1$ & 744 & 6.8 & 0.97 \\
\hline c & $\mathrm{SBA}_{190^{-1}}$ & 640 & 9.5 & 1.16 \\
\hline e & $S B A_{21}-2$ & 370 & 6.2 & 0.58 \\
\hline$f$ & $\mathrm{SBA}_{37-2}$ & 479 & 4.4 & 0.76 \\
\hline $\mathrm{g}$ & $\mathrm{SBA}_{73-2}$ & 628 & 5.6 & 0.96 \\
\hline \multicolumn{5}{|c|}{${ }^{\mathrm{a}} \mathrm{m}^{2} / \mathrm{g} .{ }^{\mathrm{b}} \mathrm{nm} \cdot{ }^{\mathrm{c}} \mathrm{cm}^{3} / \mathrm{g}$. } \\
\hline
\end{tabular}

For both $\mathbf{S B A}_{\mathbf{n}} \mathbf{- 1}$ and $\mathbf{S B A} \mathbf{n}-\mathbf{2}, g_{\text {iso }}{ }^{18}$ ranging from 2.008 to 2.010 were calculated from graphically determined $g_{\perp}$ and $g_{/ / \text {. These }}$ values were consistent with the formation of an arylsulfanyl radical. The half-lifetimes of the anchored arylsulfanyl radicals were measured by monitoring the decay of the signal intensity after turning off the irradiation. They were determined from the double integrated EPR signal. The decay curves were fitted with exponential or multi-exponential models which did not allow the mechanism involved to be determined. Several competitive processes are likely to participate to the signal decay. The half-lifetimes were graphically estimated from the fitted decay curves. The radical half-lifetimes recorded for the arylsulfanyl radicals generated from the various hybrid materials are collected in Table 2.

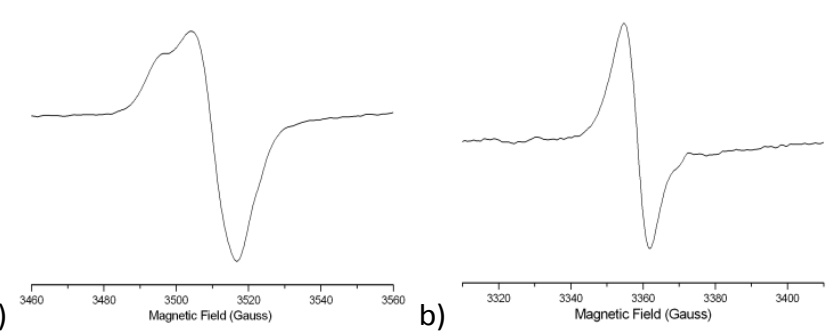
Fig. 1 EPR spectra for (a) the photolysis at $293 \mathrm{~K}$ and for (b) the thermolysis at
$473 \mathrm{~K}$ of $\mathrm{SBA}_{47}-1$

For diazene-based substrates $\mathbf{S B A}_{\mathbf{n}} \mathbf{- 1}$, half-lifetimes ranged from $52 \mathrm{~min}$ to $1.3 \mathrm{~h}$. The difference observed between the highest $(1 / 27$, entry a) and the lowest loading $(1 / 190$, entry $b)$ was low. Thiol-based substrates $\mathbf{S B A}_{\mathbf{n}} \mathbf{- 2}$, behaved differently. Half-lifetimes increased from $3.2 \mathrm{~h}$ for the lowest loading $(1 / 73$, entry $g)$ to more than $63 \mathrm{~h}$ for the highest loading $(1 / 21$, entry e). As the radical is identical and the loadings are similar, the reasons for the differences observed between the two types of precursors must be sought in the modification of the close environment of the radical.

Once generated, the sulfanyl radical can evolve through: (i) the formation of a S-S bond via the coupling of two sulfanyl radicals, (ii) the formation of a S-H bond via a hydrogen atom transfer (HAT) between the sulfur-centered radical and a nearby group, (iii) other termination reactions involving the material surface. In our materials, the probability to generate close radical centres is low. Therefore, the probability of dimerisation is also low. We have already shown that the coupling occurs without activation barrier when the two radicals are correctly positioned, but is hindered otherwise. ${ }^{11}$ 
Table 2 Half-lifetime of the arylsulfanyl radicals generated at $293 \mathrm{~K}$ by photolysis of $\mathrm{SBA}_{\mathrm{n}}-1$ and $\mathrm{SBA}_{\mathrm{n}}-2$

\begin{tabular}{|c|c|c|c|c|c|c|}
\hline & Silica & $\mathrm{g}_{/ /}$ & $\mathrm{g}_{\perp}$ & $\mathrm{g}_{\text {iso }}{ }^{\mathrm{a}}$ & $t_{1 / 2}^{b}$ & density \\
\hline a & $\mathrm{SBA}_{27}-1$ & 2.015 & 2.006 & 2.009 & $1.3 \mathrm{~h}$ & 0.67 \\
\hline b & $\mathrm{SBA}_{47}-1$ & 2.015 & 2.006 & 2.009 & $52 \mathrm{~min}$ & 0.24 \\
\hline c & $S B_{190}-1$ & 2.014 & 2.006 & 2.009 & $52 \mathrm{~min}$ & 0.08 \\
\hline e & $S_{B A} A_{21}-2$ & 2.014 & 2.008 & 2.010 & $>63 \mathrm{~h}$ & 1.14 \\
\hline$f$ & $\mathrm{SBA}_{37}-2$ & 2.014 & 2.006 & 2.009 & $9.5 \mathrm{~h}$ & 0.50 \\
\hline g & $\mathrm{SBA}_{73}-2$ & 2.015 & 2.005 & 2.008 & $3.2 \mathrm{~h}$ & 0.19 \\
\hline
\end{tabular}

${ }^{\mathrm{a}} g_{\text {iso }}=\left(2 g_{\perp}+g_{/ /}\right) / 3 .{ }^{\mathrm{b}}$ Determined from the double integrated EPR signal at 293 K. ${ }^{C}$ Number of functions per $\mathrm{nm}^{2}$

Inside the hybrid materials, the studied arylsulfanyl radicals are anchored and have no flexibility nearby the radical center. Therefore, steric hindrance, which increases with the loading, disfavors the disulfide formation. The coupling process is slowed down at the highest loadings, ${ }^{11}$ which is consistent with the slight increase of $t_{1 / 2}$ registered for $\mathbf{S B A}_{27}-\mathbf{1}$ compared to $\mathrm{SBA}_{\mathbf{4}} \mathbf{- 1}$ and $\mathrm{SBA}_{\mathbf{1 9 0}} \mathbf{- 1}$ (Table 2, entries a-c).

In the case of $\mathbf{S B A}_{\mathbf{n}} \mathbf{- 2}$, degenerate HAT between a thiol group and a sulfanyl radical occurs readily. Whereas, movements of the whole chain are needed to position properly the two reacting sulfur atoms for dimerisation, degenerate HAT occurs at larger S...S distances and only requires that a $\mathrm{S}-\mathrm{H}$ bond and the sulfur atom of a neighbouring sulfanyl radical are aligned, which is facilitated by the free rotation around the C-S bond. In order to visualize how easily could HAT proceed at the surface of the different materials, $a b$ initio simulations of a very simple model system composed of one chain of $\mathrm{CH}_{3}-\mathrm{CH}_{2}-\mathrm{CH}_{2}-\mathrm{O}-\mathrm{Ph}-\mathrm{SH}$ and one chain of $\mathrm{CH}_{3}-\mathrm{CH}_{2}-\mathrm{CH}_{2}-\mathrm{O}-\mathrm{Ph}-\mathrm{S}^{\bullet}$ were performed. The energy landscape of such a system shows a very large number of transition states (TS) for the degenerate HAT, according to the geometry of the chains approach. This approach can be characterized by the C-S...S-C dihedral angle $(\phi)$. Therefore, an energy scan has been performed at the B3LYP-6-311+G(d,p) level of theory, searching for transition states and varying $\phi$. All the transitions states found have $\mathrm{S}, \mathrm{H}$ and $\mathrm{S}$ atoms aligned with a distance between the two sulfur atoms equal to $3.2 \AA$. This scan shows (Fig. 2) that TS for the degenerate HAT can be found when the distance between the terminal groups of the chains (i.e. the carbons that should be linked to the silica) $d_{T}$ is comprised between $7.5 \AA$ (when the torsion is close to $0^{\circ}$ ) and $19.5 \AA$ (when the torsion is close to $180^{\circ}$ ). When the surface functional density grows larger than 1.8 functions per $\mathrm{nm}^{2}, \mathrm{~d}_{\mathrm{T}}$ becomes smaller than $7.5 \AA$ and the steric hindrance keeps the sulfur atoms at a distance larger than $3.2 \AA$, preventing HAT. When the surface functional density diminishes below 0.25 functions per $\mathrm{nm}^{2}, \mathrm{~d}_{\mathrm{T}}$ becomes larger than $19.5 \AA$ and the sulfur atoms become too far away to perform HAT.

Reaction paths for six of these TS have been followed by integrating the intrinsic reaction coordinate (IRC). The energy barrier for degenerate HAT have been evaluated from the stationary points of these IRC scans. It is small and does not vary significantly with the terminal groups distance or the dihedral angle: $\Delta \mathrm{G}^{\neq}$varies from 5.8 to $9.0 \mathrm{kcal} \mathrm{mol}^{-1}$, while $\Delta \mathrm{H}^{\neq}$ varies from 4.4 to $5.0 \mathrm{kcal}^{\mathrm{mol}^{-1}}$ (c.f. Supplementary Information). The energies for the simplest system (Ph-SH + $\mathrm{Ph}-\mathrm{S}^{\circ}$ ) have been evaluated using the G3(MP2)RAD procedure $^{19}$ in order to validate that the $B 3 L Y P / 6-311+G(d, p)$ level of theory gives reasonable energy values. For this system, the $B 3 L Y P / 6-311+G(d, p)$ activation parameters are $\Delta G^{7}=8.2$

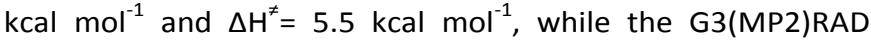

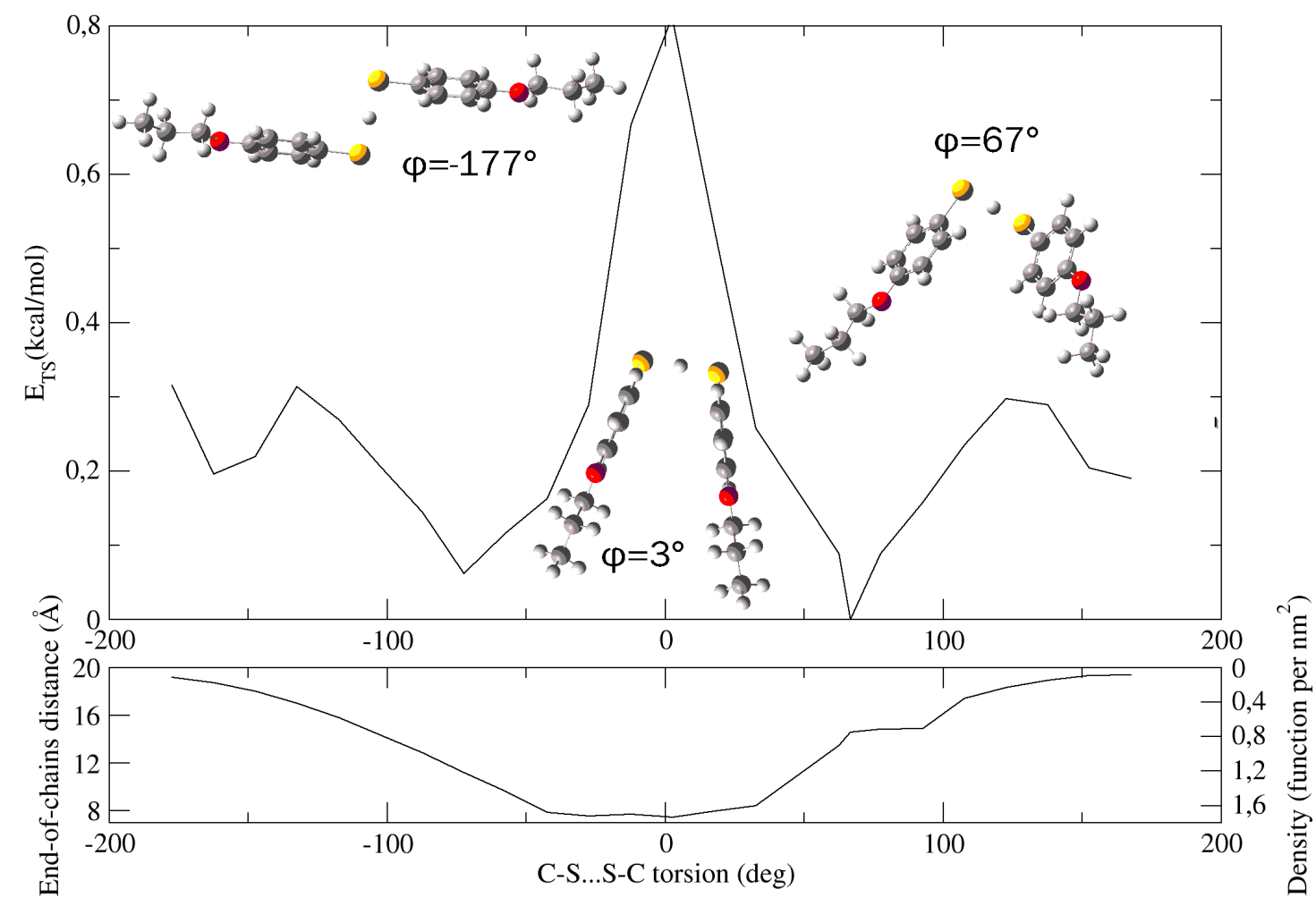

Fig. 2 Energy scan of TS for HAT. The functional density was estimated from the end-of-chains distance by supposing that functions are spread on the surface in a regular square pattern. 
values are $\Delta \mathrm{G}^{7}=8.3 \mathrm{kcal} \mathrm{mol}^{-1}, \Delta \mathrm{H}^{\neq}=5.7 \mathrm{kcal} \mathrm{mol}{ }^{-1}$. According to these results, among the loadings tested experimentally, the probability that a HAT could happen is small for $\mathbf{S B A}_{\mathbf{7 3}} \mathbf{- 2}$ (as the number of chains is small and the distance between chains is large), but becomes larger when the loading rises (SBA $\mathbf{2 7}_{\mathbf{2}} \mathbf{- 2}$ and $\mathbf{S B A}_{21}-\mathbf{2}$ ) as the conditions for HAT are geometrically favourable and the number of chains (therefore the number of possible contacts between chains) grows. This degenerate transfer would propagate all along the pore surface until a termination reaction becomes faster than the next available HAT. ${ }^{20}$ Quantum mechanical tunneling (QMT) increases the efficiency of HAT. ${ }^{21}$ Calculations showed that the degenerate HAT is at least two times faster than classical thermodynamics would have predicted (see ESI). This process can be related to the proton transport in acid functionalized mesoporous material. $^{22}$

In the case of $\mathbf{S B A}_{\mathbf{n}} \mathbf{- 1}$, the termination reaction leading to a disulfide can still take place but the absence of thiol groups in the close vicinity precludes degenerate HAT. However, due to the structural features of the precursor, other reactions can be considered that might contribute to the decay of the sulfanyl radical signal.

Hydrogen atom transfer from the methylene or a methyl group of a neighbouring diazene can be envisaged, but this transfer is enthalpically disfavoured (BDE ArS-H $=77.8 \mathrm{kcal} \mathrm{mol}^{-1} / \mathrm{C}_{\mathrm{sp3}}-\mathrm{H}$ $=92.1$ or $\left.100.5 \mathrm{kcal} \mathrm{mol}^{-1}\right)$. ${ }^{23}$ The generation of such a carboncentered radical should trigger a $\beta$-fragmentation releasing a diazenyl radical and consequently another $t$-butyl radical. Thus, the fate of $t$-butyl radical must also be considered. The latter is likely to diffuse rapidly in the silica pore and dimerize or disproportionate. Moreover, it could reduce the lifetime of the arylsulfanyl radical. First, via a recombination process that would lead to the corresponding $t$-butylsulfide. In addition, as it is a good hydrogen atom donor since its $\mathrm{C}-\mathrm{H}$ BDE was estimated $36.7 \mathrm{kcal} \mathrm{mol}^{-1},{ }^{24}$ it could deliver a hydrogen atom to an arylsulfanyl radical. This would lead to a thiol mainly surrounded by diazene precursors which in turn would generate another sulfanyl radical under irradiation. It must be underlined that no $t$-butyl radical was ever detected in any of the reported EPR experiments. This observation argues in favour of a fast evolution of the $t$-butyl radicals that would occur before the decay of arylsulfanyl radical starts being monitored. For the above mentioned reasons, these processes should not contribute significantly to the observed phenomenon, the average half-lifetime ( 1h) remains considerably increased compared to the $200 \mu$ s half-lifetime reported for phenylsulfanyl radical in solution. ${ }^{12}$

In summary, the most impressive change in half-lifetime for a given type of arylsulfanyl radical according to the nature of the precursor is intimately connected to the availability of a fast HAT. In the case of diazene precursors, the absence of fast HAT increases the probability of termination reactions.

Independently, the thermolysis of dissymmetric diazenes $\mathbf{S B A}_{\mathbf{n}}-\mathbf{1}$ localized on the pore was investigated. The influence of the localization (wall/pore) on the arylsylfanyl radical lifetime was evaluated by comparison with the data obtained from symmetric diazenes embedded in the framework of the nanostructured silica. ${ }^{10}$ The thermogravimetric analysis (TGA) showed that the thermal decomposition of diazene moieties occurred at $473 \mathrm{~K}$. The decay of the corresponding arylsufanyl radicals was investigated at this temperature by EPR. Due to the temperature, the EPR signal was isotropic with a $2.009 \mathrm{~g}$ - factor (Fig. 1b), i.e. a value close to the values recorded at 293 $\mathrm{K}$ (Table 3).

Table 3 Half-lifetime of the aryl sulfanyl radicals generated at $473 \mathrm{~K}$ by thermolysis on $\mathrm{SBA}_{\mathrm{n}}-1$

\begin{tabular}{cccc}
\hline & Silica & $\mathrm{g}$ & $\mathrm{t}_{1 / 2}(\mathrm{~min})^{\mathrm{a}}$ \\
\hline a & $\mathbf{S B A}_{27}-\mathbf{1}$ & 2,009 & 13 \\
b & $\mathbf{S B A}_{47}-\mathbf{1}$ & 2,009 & 12 \\
C & $\mathbf{S B A}_{47} \mathbf{1}^{*}$ & 2,009 & 3 \\
\multicolumn{2}{l}{ a Determined from the double integrated EPR signal at 473K. } \\
\hline
\end{tabular}

The half-lifetimes of the anchored arylsulfanyl radicals were measured by monitoring the decay of the signal of highest intensity. They were in the same order of magnitude than those registered when the symmetric diazene precursor was located in the wall of the silica. ${ }^{10}$ The registered values (approximately $12 \mathrm{~min}$ ) were still much higher than the reference value reported by Thyrion in solution at room temperature $(200 \mu \mathrm{s}) .^{12}$ At such a temperature, neither the effect of the monolayer structure nor passivation did improve the radical lifetime. For the sake of comparison, the same experiment was performed with $\mathbf{S B A}_{\mathbf{n}}-\mathbf{2}$. The heating of $\mathbf{S B A} \mathbf{n}-\mathbf{2}$ at $473 \mathrm{~K}$ led to the generation of a weak EPR signal probably due to a weak efficiency of the thermal homolysis of the S-H bond. An additional irradiation did not enable to improve the signal intensity. This difference in behaviour showed the diazene precursor is the most appropriate precursor to observe arylsulfanyl radicals at high temperature.

\section{Conclusions}

Progress in the synthesis of nanostructured silicas enables the identification of the phenomenons responsible for the transformation of a transient arylsulfanyl radical into a persistent one. The comparison of the behaviour of arylsulfanyl radicals generated from two different precursors highlights the importance of the radical surroundings.

At room temperature, the persistence of arylsulfanyl radicals derived from diazene precursors ( $1 \mathrm{~h} / 200 \mu \mathrm{s}$ in solution) results from the intrinsic effect of confinement which slows down the formation of disulfide likely to be the main source of decay of their EPR signal. Potential minor causes of signal decay, that must be sought in the structure of the diazene moiety in the precursor, are discussed even though their involvement could not be ascertained.

The contrasting behaviour of thiol derived radicals, which exhibit a spectacular increase in half-lifetime (up to $63 \mathrm{~h}$ ) is rationalized on the basis of fast degenerate HAT from thiol groups in the close vicinity which competes with the termination processes. From this experimental comparative study, supported by calculation, we concluded that in the case of aromatic thiol, the amazing half-lifetimes recorded result from the synergistic effects of the structure of the organic monolayer and the fast degenerate HAT. This HAT process is a dynamic phenomenon which contrasts with the steric and/or 
electronic effects that are commonly used to improve radical lifetimes.

At $473 \mathrm{~K}$ the situation is reversed, the occurrence of HAT no longer improves the lifetime of the sulfanyl radicals generated from thiol precursors, diazene precursors were more efficient as regard to the radical persistence.

\section{Experimental}

\section{General}

All reactions were carried out in dry glassware using magnetic stirring and under argon. Commercially available solvents were used as purchased, without further purification. $\mathrm{CH}_{2} \mathrm{Cl}_{2}$ was distilled over $\mathrm{CaH}_{2}$ and stored under dry conditions. THF was distilled over sodium benzophenone ketyl prior to use. Dry state adsorption conditions and purification were performed on Macherey Nagel silica gel $60 \AA$ (70-230 mesh). Analytical thin layer chromatography was performed on pre-coated silica gel plates. Visualization was accomplished by UV $(254 \mathrm{~nm})$ and with phosphomolybdic acid in ethanol. ${ }^{1} \mathrm{H} N M R,{ }^{13} \mathrm{C} N M R$ spectra were recorded on a 300 or a $400 \mathrm{MHz}$ spectrometer. Chemical shifts $(\delta)$ are reported in ppm. Signals due residual protonated solvent $\left({ }^{1} \mathrm{H}\right.$ NMR) or to the solvent $\left({ }^{13} \mathrm{C} N M R\right)$ served as the internal standard: $\mathrm{CDCl}_{3}(7.27 \mathrm{ppm}$ and 77.0 $\mathrm{ppm})$. Multiplicity is indicated by one or more of the following: $\mathrm{s}$ (singlet), d (doublet), t (triplet), q (quartet), quint (quintet), $\mathrm{m}$ (multiplet), br (broad). The lists of coupling constants (J) correspond to the order of multiplicity assignment and are reported in Hertz (Hz). APT was used for ${ }^{13} \mathrm{C}$ spectra assignment. All melting points were uncorrected and were recorded in open capillary tubes using a melting point apparatus.

4-Hydroxythiophenol and diethyl 2,2'-azobis(2methylpropionate) are commercially available, they were used as purchased without purification. 4-(Prop-2-en-1yloxy)benzenethiol (4) was prepared according to a literature procedure. $^{11}$

\section{Methyl}

2-[N-(tert-butyl)aminosulfonamido]-2methylpropanoate (8). To a solution of methyl $\alpha$ aminoisobutanoate hydrochloride (9) $(4.0 \mathrm{~g}, 26.0 \mathrm{mmol}, 1$ equiv) in acetonitrile $(45 \mathrm{~mL})$ was added sulfuryl chloride $(3.51$ g, $26.0 \mathrm{mmol}, 1$ equiv) at room temperature. The mixture was stirred for 7 hours at $80{ }^{\circ} \mathrm{C}$. Sulfuryl chloride (3.51 g, 26.0 mmol, 1 equiv) was again added and the solution was stirred overnight at $80{ }^{\circ} \mathrm{C}$. After cooling and evaporation of the solvent, the residue was triturated with $\mathrm{Et}_{2} \mathrm{O}$ ( 3 times). $\mathrm{Et}_{2} \mathrm{O}$ phase was dried over $\mathrm{MgSO}_{4}$. After concentration, the corresponding sulfamoyl chloride was obtained (4.82 g, 22.4 $\mathrm{mmol}, 86 \%)$ and used without further purification. ${ }^{1} \mathrm{H}$ NMR $\left(400 \mathrm{MHz}, \mathrm{CDCl}_{3}\right) \delta: 6.90(\mathrm{br} \mathrm{s}, 1 \mathrm{H}, \mathrm{NH}), 3.84\left(\mathrm{~s}, 3 \mathrm{H}, \mathrm{OCH}_{3}\right), 1.73$ $\left(\mathrm{s}, 6 \mathrm{H}, 2 \times \mathrm{CH}_{3}\right) \cdot{ }^{13} \mathrm{C} \mathrm{NMR}\left(100 \mathrm{MHz}, \mathrm{CDCl}_{3}\right) \delta: 173.5(\mathrm{CO}), 61.6$ $\left(\mathrm{OCH}_{3}\right), 53.7$ (C), $24.6\left(2 \mathrm{xCH}_{3}\right)$. To a $0{ }^{\circ} \mathrm{C}$ solution of freshly prepared sulfamoyl chloride (4.82 $\mathrm{g}, 22.4 \mathrm{mmol}, 1$ equiv) in $\mathrm{CH}_{2} \mathrm{Cl}_{2}(45 \mathrm{~mL})$ was added $t$-butylamine $(4.92 \mathrm{~g}, 67.2 \mathrm{mmol}, 3$ equiv). The mixture was stirred at room temperature. The reaction was monitored by TLC. After completion ( $2 \mathrm{~h}$ ), the mixture was diluted with water and extracted three times with
EtOAc. Organic extracts were washed successively with $\mathrm{HCl}(1$ $\mathrm{N})$, water, brine and then dried over $\mathrm{MgSO}_{4}$. After concentration, sulfonamide 8 (5.03 g, $19.9 \mathrm{mmol}, 89 \%)$ was obtained and used without further purification. ${ }^{1} \mathrm{H}$ NMR (400 $\mathrm{MHz}, \mathrm{CDCl}_{3}$ ) $\delta: 4.93(\mathrm{br} \mathrm{s}, 1 \mathrm{H}, \mathrm{NH}), 4.19(\mathrm{br} \mathrm{s}, 1 \mathrm{H}, \mathrm{NH}), 3.77(\mathrm{~s}$, $\left.3 \mathrm{H}, \mathrm{OCH}_{3}\right), 1.55\left(\mathrm{~s}, 6 \mathrm{H}, 2 \times \mathrm{CH}_{3}\right), 1.36\left(\mathrm{~s}, 3 \mathrm{xCH}_{3}\right) .{ }^{13} \mathrm{C} \mathrm{NMR}(100$ $\left.\mathrm{MHz}, \mathrm{CDCl}_{3}\right)$ ठ: $175.6(\mathrm{CO}), 59.0(\mathrm{C}), 54.6(\mathrm{C}), 52.8\left(\mathrm{OCH}_{3}\right), 29.9$ $\left(3 \times \mathrm{CH}_{3}\right), 25.6\left(2 \times \mathrm{CH}_{3}\right)$. HRMS (ESI): $\mathrm{m} / \mathrm{z}$ : calcd for $[\mathrm{M}+\mathrm{H}]^{+}$ $\mathrm{C}_{9} \mathrm{H}_{21} \mathrm{~N}_{2} \mathrm{O}_{4} \mathrm{~S}: 253.1217$, found: 253.1218 .

(E)-Methyl 2-(2-tert-butyldiazenyl)-2-methylpropanoate (7). To a solution of 8 ( $2.0 \mathrm{~g}, 7.9 \mathrm{mmol}, 1$ equiv) in pentane $(10 \mathrm{~mL})$ was slowly added $\mathrm{NaOH}(652 \mathrm{mg}, 16.3 \mathrm{mmol})$ in $\mathrm{NaOCl}(29 \mathrm{~mL}$, $0.56 \mathrm{M})$. The mixture was stirred for 2 hours at room temperature. The mixture was diluted with water and extracted three times with pentane. Organic extracts were washed with brine and then dried over $\mathrm{MgSO}_{4}$. After concentration, diazene 7 (670 $\mathrm{mg}, 3.6 \mathrm{mmol}, 46 \%)$ was obtained and used without further purification. ${ }^{1} \mathrm{H}$ NMR (400 $\left.\mathrm{MHz} \mathrm{CDCl}_{3}\right) \delta: 3.69\left(\mathrm{~s}, 3 \mathrm{H}, \mathrm{OCH}_{3}\right), 1.42\left(\mathrm{~s}, 6 \mathrm{H}, 2 \mathrm{xCH}_{3}\right), 1.17(\mathrm{~s}$, $\left.6 \mathrm{H}, 3 \times \mathrm{CH}_{3}\right) .{ }^{13} \mathrm{C} \mathrm{NMR}\left(100 \mathrm{MHz}, \mathrm{CDCl}_{3}\right) \delta: 174.2(\mathrm{CO}), 74.4(\mathrm{C})$, 68.9 (C), $51.8\left(\mathrm{CH}_{3}\right), 26.4\left(3 \mathrm{xCH}_{3}\right), 22.8\left(2 \mathrm{xCH}_{3}\right)$. HRMS (ESI): $\mathrm{m} / \mathrm{z}$ : calcd for $[\mathrm{M}+\mathrm{H}]^{+} \mathrm{C}_{9} \mathrm{H}_{19} \mathrm{~N}_{2} \mathrm{O}_{2}$ : 187.1441, found: 187.1434 .

(E)-2-(2-tert-Butyldiazenyl)-2-methylpropan-1-ol (6). To a suspension of $7\left(710 \mathrm{mg}, 3.8 \mathrm{mmol}, 1\right.$ equiv) in $\mathrm{Et}_{2} \mathrm{O}(8 \mathrm{~mL})$ under argon was added at $0{ }^{\circ} \mathrm{C}$ lithium aluminum hydride (152 $\mathrm{mg}, 4 \mathrm{mmol}, 1.05$ equiv). The mixture was stirred for 2 hours at room temperature. After completion (TLC monitoring), $\mathrm{Na}_{2} \mathrm{SO}_{4} \bullet 10 \mathrm{H}_{2} \mathrm{O}(1.2 \mathrm{~g}, 3.8 \mathrm{mmol}, 1$ equiv) was added and the mixture was stirred for one night at room temperature, before being filtrated on Celite, dried over $\mathrm{MgSO}_{4}$ and concentrated to give product $6(529 \mathrm{mg}, 3.34 \mathrm{mmol}, 88 \%)$ that was used directly without further purification. ${ }^{1} \mathrm{H}$ NMR $\left(400 \mathrm{MHz}, \mathrm{CDCl}_{3}\right)$ $\delta: 3.63\left(\mathrm{~s}, 2 \mathrm{H}, \mathrm{CH}_{2}\right), 2.71$ (br s, $\left.1 \mathrm{H}, \mathrm{OH}\right), 1.19\left(\mathrm{~s}, 6 \mathrm{H}, 2 \mathrm{xCH}_{3}\right)$, $1.17\left(\mathrm{~s}, 3 \times \mathrm{CH}_{3}\right) .{ }^{13} \mathrm{C} \mathrm{NMR}\left(75 \mathrm{MHz}, \mathrm{CDCl}_{3}\right) \delta: 69.1\left(\mathrm{CH}_{2}\right), 68.9$ (C), 66.8 (C), $26.6\left(3 \times \mathrm{CH}_{3}\right), 21.9\left(2 \times \mathrm{CH}_{3}\right)$. HRMS (ESI): $\mathrm{m} / \mathrm{z}$ : calcd for $[\mathrm{M}+\mathrm{H}]^{+} \mathrm{C}_{8} \mathrm{H}_{19} \mathrm{~N}_{2} \mathrm{O}: 159.1412$, found: 159.1491 .

2-[(E)-2-[1-(Methansulfonyloxy)-2-methylpropan-2-yl]diazen1-yl]-2-methyl propane (5). To alcohol 6 (1.19 g, $7.5 \mathrm{mmol}, 1$ equiv) and triethylamine (1.08 g, $10.7 \mathrm{mmol}, 1.4$ equiv) in $\mathrm{CH}_{2} \mathrm{Cl}_{2}(90 \mathrm{~mL})$ under argon was slowly added methanesulfonyl chloride $\left(1.02 \mathrm{~g}, 8.9 \mathrm{mmol}, 1.2\right.$ equiv) at $0{ }^{\circ} \mathrm{C}$. The reaction mixture was allowed to warm slowly to room temperature. After $1 \mathrm{~h}$ (TLC monitoring), the mixture was diluted with water, washed with $1 \mathrm{M} \mathrm{HCl}$ and brine and then dried over $\mathrm{MgSO}_{4}$. After concentration, the corresponding mesylate $\mathbf{5}$ was obtained (1.75 g, $7.4 \mathrm{mmol}, 99 \%)$ and used without further purification. ${ }^{1} \mathrm{H}$ NMR (300 MHz, $\left.\mathrm{CDCl}_{3}\right) \delta: 4.31\left(\mathrm{~s}, 2 \mathrm{H}, \mathrm{CH}_{2}\right)$, 2.96, (s, 3H, O $\left.\mathrm{O}_{2} \mathrm{SCH}_{3}\right), 1.16\left(\mathrm{~s}, 6 \mathrm{H}, \mathrm{CH}_{3}\right), 1.13\left(\mathrm{~s}, 9 \mathrm{H}, \mathrm{CH}_{3}\right) .{ }^{13} \mathrm{C}$ $\mathrm{NMR}\left(75 \mathrm{MHz}, \mathrm{CDCl}_{3}\right)$ 8: $76.7\left(\mathrm{CH}_{2}\right), 67.5(\mathrm{C}-\mathrm{N}), 67.0(\mathrm{C}-\mathrm{N}), 37.1$ $\left(\mathrm{CH}_{3}\right), 26.6\left(\mathrm{CH}_{3}\right), 21.7\left(\mathrm{CH}_{3}\right)$. HRMS (ESI): $\mathrm{m} / \mathrm{z}$ : calcd for $[\mathrm{M}+\mathrm{H}]^{+}$ $\mathrm{C}_{9} \mathrm{H}_{21} \mathrm{~N}_{2} \mathrm{O}_{3} \mathrm{~S}: 237.1267$, found: 237.1268 .

(E)-2-(1-(4-(Allyloxy)phenylthio)-2-methylpropan-2-yl)-1-tertbutyldiazene (3). A suspension of sodium (177 mg, $7.7 \mathrm{mmol}, 1$ equiv) in $\mathrm{MeOH}(15 \mathrm{~mL}$ ) under argon was stirred until the reaction was completed. The thiophenol $4(1.28 \mathrm{~g}, 7.7 \mathrm{mmol}, 1$ equiv) dissolved in $\mathrm{MeOH}(2 \mathrm{~mL})$ was added at $0{ }^{\circ} \mathrm{C}$ and the mixture was stirred for $15 \mathrm{~min}$ at room temperature. The 
solvent was evaporated and the residue diluted with $\mathrm{Et}_{2} \mathrm{O}$ before being filtrated. The residue was washed with $\mathrm{Et}_{2} \mathrm{O}$ and dried under vacuum to give the expected thiolate as a pale yellow solid (1.39 g, $7.4 \mathrm{mmol}, 96 \%)$ that was used without further purification. A suspension of mesylate 5 (1.75 g, 7.4 mmol, 1 equiv) and the freshly prepared sodium salt $(1.39 \mathrm{~g}$, $7.4 \mathrm{mmol}, 1$ equiv) in DMF ( $6 \mathrm{~mL}$ ) under argon was stirred for one night at $50{ }^{\circ} \mathrm{C}$. The reaction was monitored by TLC. After completion, the mixture was diluted with water and extracted four times with EtOAc. Organic extracts were washed with water, brine, dried over $\mathrm{MgSO}_{4}$ and concentrated. The residue was purified using a silica gel column (1-2\% $\mathrm{Et}_{2} \mathrm{O}$ in pentane) to give 3 as a yellow oil $(1.1 \mathrm{~g}, 3.6 \mathrm{mmol}, 49 \%) .{ }^{1} \mathrm{H}$ NMR (400 $\left.\mathrm{MHz} \mathrm{CDCl}_{3}\right) \delta: 7.33(\mathrm{~d}, J=8.8 \mathrm{~Hz}, 2 \mathrm{H}, \operatorname{ArH}), 6.82(\mathrm{~d}, J=8.8 \mathrm{~Hz}$, $2 \mathrm{H}, \mathrm{ArH}$ ), 6.04 (ddt, $J=17.2,10.5,5.3 \mathrm{~Hz}, 1 \mathrm{H}, \mathrm{CH}=\mathrm{CH}_{2}$ ), 5.40 (dq, $J=17.3,1.5 \mathrm{~Hz}, 1 \mathrm{H}, \mathrm{CH}=\mathrm{CH}_{2}$ ), 5.28 (dq, $J=10.5,1.5 \mathrm{~Hz}, 1 \mathrm{H}$, $\left.\mathrm{CH}=\mathrm{CH}_{2}\right), 4.50\left(\mathrm{dt}, J=5.3,1.5 \mathrm{~Hz}, 2 \mathrm{H}, \mathrm{OCH}_{2}\right), 3.17\left(\mathrm{~s}, 2 \mathrm{H}, \mathrm{SCH}_{2}\right)$, $1.22\left(\mathrm{~s}, 6 \mathrm{H}, \mathrm{CH}_{3}\right), 1.15\left(\mathrm{~s}, 9 \mathrm{H}, \mathrm{CH}_{3}\right) .{ }^{13} \mathrm{C} \mathrm{NMR}\left(100 \mathrm{MHz}, \mathrm{CDCl}_{3}\right)$ $\delta: 157.6\left(\mathrm{C}_{\mathrm{Ar}}-\mathrm{O}\right), 133.2\left(\mathrm{CH}=\mathrm{CH}_{2}\right), 132.6(\mathrm{CH}), 128.9\left(\mathrm{SC}_{\mathrm{Ar}}\right)$, $117.7\left(\mathrm{CH}=\mathrm{CH}_{2}\right), 115.3(\mathrm{CH}), 69.1(\mathrm{C}), 68.9\left(\mathrm{OCH}_{2}\right), 66.6(\mathrm{C})$, $46.8\left(\mathrm{SCH}_{2}\right), 26.7\left(3 \mathrm{xCH}_{3}\right), 24.3\left(2 \mathrm{xCH}_{3}\right)$. HRMS (ESI): $\mathrm{m} / \mathrm{z}$ : calcd for $[\mathrm{M}+\mathrm{H}]^{+} \mathrm{C}_{17} \mathrm{H}_{27} \mathrm{~N}_{2} \mathrm{OS}$ : 307.1839, found: 307.1840.

\section{(E)-2-(1-(4-(3-(Triethoxysilyl)propoxy)phenylthio)-2-}

methylpropan-2-yl)-1-tert-butyldiazene (1). To a suspension of 3 (650 mg, $2.12 \mathrm{mmol}, 1$ equiv) in triethoxysilane $(1.18 \mathrm{~mL}$, $6.36 \mathrm{mmol}, 3$ equiv) under argon was added Karstedt's catalyst $(0.1 \mathrm{~mL})$. The mixture was stirred for one night at room temperature. The reaction was monitored by ${ }^{1} \mathrm{H}$ NMR. After completion, the mixture was evaporated, diluted with pentane and filtrated under argon. This operation was repeated twice. The pentane solution was concentrated to give 1 as a yellow oil (997 g, $2.11 \mathrm{mmol}, 99 \%) .{ }^{1} \mathrm{H}$ NMR (400 MHz, $\mathrm{CDCl}_{3}$ ) $\delta: 7.33$ (d, $J=8.8 \mathrm{~Hz}, 2 \mathrm{H}, \operatorname{ArH}), 6.80(\mathrm{~d}, J=8.8 \mathrm{~Hz}, 2 \mathrm{H}, \operatorname{ArH}), 3.91(\mathrm{t}, J=$ $6.7 \mathrm{~Hz}, 2 \mathrm{H}, \mathrm{OCH}_{2} \mathrm{CH}_{2}$ ), 3.83 (q, $J=7.0 \mathrm{~Hz}, 6 \mathrm{H}, \mathrm{OCH}_{2} \mathrm{CH}_{3}$ ), 3.16 (s, $2 \mathrm{H}, \mathrm{SCH}_{2}$ ), 1.89 (quint, $J=6.7 \mathrm{~Hz}, 2 \mathrm{H}, \mathrm{OCH}_{2} \mathrm{CH}_{2}$ ), $1.23(\mathrm{t}, J=7.0$ $\mathrm{Hz}, 9 \mathrm{H}, \mathrm{OCH}_{2} \mathrm{CH}_{3}$ ), 1.22 (superimposed $\mathrm{s}, 6 \mathrm{H}, \mathrm{CH}_{3}$ ), 1.15 (s, $9 \mathrm{H}$, $\left.3 \times \mathrm{CH}_{3}\right), 0.75\left(\mathrm{t}, \mathrm{J}=8.3 \mathrm{~Hz}, 2 \mathrm{H}, \mathrm{SiCH}_{2}\right) .{ }^{13} \mathrm{C} \mathrm{NMR}(100 \mathrm{MHz}$, $\left.\mathrm{CDCl}_{3}\right)$ \&: $158.1\left(\mathrm{C}_{\mathrm{Ar}} \mathrm{O}\right), 132.7\left(\mathrm{CH}=\mathrm{CH}_{2}\right), 128.4\left(\mathrm{SC}_{\mathrm{Ar}}\right), 115.1$ $\left(\mathrm{CH}=\mathrm{CH}_{2}\right), 70.0\left(\mathrm{OCH}_{2}\right), 69.5(\mathrm{C}-\mathrm{N}), 66.5(\mathrm{C}-\mathrm{N}), 58.4\left(\mathrm{OCH}_{2}\right), 47.0$ $\left(\mathrm{SCH}_{2}\right), 26.7\left(3 \times \mathrm{CH}_{3}\right), 24.3\left(2 \mathrm{xCH}_{3}\right), 22.8\left(\mathrm{CH}_{2}\right), 18.3\left(3 \mathrm{xCH}_{3}\right), 6.5$ $\left(\mathrm{SiCH}_{2}\right)$. HRMS (ESI): $\mathrm{m} / \mathrm{z}$ : calcd for $[\mathrm{M}+\mathrm{H}]^{+} \mathrm{C}_{23} \mathrm{H}_{43} \mathrm{~N}_{2} \mathrm{O}_{4} \mathrm{SSi}$ : 471.2707, found: 471.2709 .

Experimental procedures for the synthesis and characterisation of materials: Thermogravimetric (TGA) measurements were carried out with a TGA Q500 apparatus (TA Instruments) under dynamic air atmosphere (sample flow rate $40 \mathrm{ml} / \mathrm{min}$ ). SAXS experiments were performed on SAXSess-MC2 (Anton-Paar, GmbH, Austria) with a sealed copper tube as X-ray source (wavelength is $0.15417 \mathrm{~nm}$ (Cu K$\alpha)$ ) and CCD camera as detection system. The $\mathrm{N}_{2}$ adsorption/desorption isotherms were obtained at $77 \mathrm{~K}$ on a Micrometrics ASAP2010. The specific surface area was determined according to the Brunauer, Emmett and Teller (BET) method and the pore size distribution was calculated from the desorption isotherms using the Barrett Joyner Halenda (BJH) method. ${ }^{25}$ Prior to adsorption, the samples were outgassed at $353 \mathrm{~K}$ overnight under a vacuum pressure of $2 \times 10^{-3}$ mbar. All solid-state Cross Polarization Magic Angle Spinning (CPMAS) NMR spectra were obtained on a Bruker Avance-400 MHz NMR spectrometer operating at ${ }^{13} \mathrm{C}$ and ${ }^{29} \mathrm{Si}$ resonance frequencies of $101.6 \mathrm{MHz}$ and $79.5 \mathrm{MHz}$, respectively. ${ }^{13} \mathrm{C}$ and ${ }^{29} \mathrm{Si}$ CPMAS experiments were performed with a commercial Bruker double-bearing probe. About 100 $\mathrm{mg}$ of samples were placed in zirconium dioxide rotors of 4 $\mathrm{mm}$ outer diameter and spun at a Magic Angle Spinning rate of $10 \mathrm{kHz}$. The CP technique ${ }^{26}$ was applied with a ramped ${ }^{1} \mathrm{H}-$ pulse starting at $100 \%$ power and decreasing down to $50 \%$ during the contact time in order to circumvent HartmannHahn mismatches. ${ }^{27,28}$ The contact times were $2 \mathrm{~ms}$ for ${ }^{13} \mathrm{C}$ CPMAS and $5 \mathrm{~ms}$ for ${ }^{29} \mathrm{Si}$ CPMAS. To improve the resolution, a dipolar decoupling GT8 pulse sequence ${ }^{29}$ was applied during the acquisition time. In order to obtain a good signal-to-noise ratio, 6144 scans were accumulated using a delay of $2 \mathrm{~s}$ in ${ }^{13} \mathrm{C}$ CPMAS experiment, and 4096 scans with a delay of $5 \mathrm{~s}$ in ${ }^{29} \mathrm{Si}$ CPMAS experiment. The ${ }^{13} \mathrm{C}$ and ${ }^{29} \mathrm{Si}$ chemical shifts were referenced to tetramethylsilane. Commercially available tetraethylorthosilicate (TEOS) was distilled before used. $\mathbf{S B A}_{\mathbf{n}} \mathbf{- 2}$ was prepared according to a literature procedure. ${ }^{11}$

Synthesis of Materials $\mathrm{SBA}_{\mathbf{n}}-\mathbf{1}$ :

SBA $_{27}-1$ : In a typical procedure, pluronic P-123 (2 g) in deionized water $(14 \mathrm{~mL}$ ) and $2 \mathrm{M}$ hydrochloric acid solution (60 $\mathrm{mL}$ ) was stirred for $3 \mathrm{~h}$ at $40{ }^{\circ} \mathrm{C}$. Tetraethoxysilane $(2.0 \mathrm{~mL}, 9.0$ mmol, 9 equiv) and organic precursor $1(471 \mathrm{mg}, 1.0 \mathrm{mmol}, 1$ equiv) were added. The mixture was stirred for $24 \mathrm{~h}$ at $40{ }^{\circ} \mathrm{C}$, then warmed without stirring at $100{ }^{\circ} \mathrm{C}$ for 2 days, filtrated, washed twice with water, once with ethanol and finally extracted with a Soxlhet apparatus (ethanol) for one day. The wet powder was filtrated, washed twice with ethanol, acetone and diethylether. After one night at $80{ }^{\circ} \mathrm{C}$ under vacuum, a pale yellow powder was recovered. The molar composition of the isolated mixture was as follows: (1-x) M TEOS: $x$ M 1: 0.017 M P123 Polymer: $188 \mathrm{M} \mathrm{H}_{2} \mathrm{O}: 5.8 \mathrm{M} \mathrm{HCl}$, where $x$ denotes the number of moles of precursor $1 .{ }^{13} \mathrm{C}$ CPMAS NMR $(101.6 \mathrm{MHz})$ $\delta: 157.5,132.2,130.5,127.2,114.5,74.9,69.0,46.5,25.4$, 22.6, 15.1 (P123), 7.1. ${ }^{29} \mathrm{Si}$ CPMAS NMR $(79.5 \mathrm{MHz}) \delta:-56.9$ $\left(T^{2}\right),-65.7\left(T^{3}\right)$, -92.0 $\left(Q^{2}\right),-101.4\left(Q^{3}\right),-110.0\left(Q^{4}\right)$. BET Surface Area: $451 \mathrm{~m}^{2} / \mathrm{g}$. BJH Desorption Average Pore Diameter: 5.1 nm. TGA: Mass Loss $=7.1 \%$. SAXS: No signal.

$\mathrm{SBA}_{47}-1$ : Following the previous procedure, tetraethoxysilane (2.12 mL, $9.5 \mathrm{mmol}, 19$ equiv) and organic precursor 1 (235 mg, 0.5 mmol, 1 equiv). ${ }^{13} \mathrm{C}$ CPMAS NMR (101.6 MHz) $\delta: 156.9$, $132.4,127.9,114.4,74.9,69.4,25.1,22.5,15.2(\mathrm{P} 123), 7.7 .{ }^{29} \mathrm{Si}$ CPMAS NMR (79.5 MHz) $\delta:-57.2\left(T^{2}\right),-65.2\left(T^{3}\right),-92.1\left(Q^{2}\right)$, $101.4\left(Q^{3}\right),-110.2\left(Q^{4}\right)$. BET Surface Area: $744 \mathrm{~m}^{2} / g$. BJH Desorption Average Pore Diameter: $6.8 \mathrm{~nm}$. TGA: Mass Loss $=$ 4.4\%. SAXS: $d=11.9 \mathrm{~nm}$.

SBA $_{190}$-1: Following the previous procedure, tetraethoxysilane ( $2.17 \mathrm{~mL}, 9.75 \mathrm{mmol}, 39$ equiv) and organic precursor 1 (118 $\mathrm{mg}, 0.25 \mathrm{mmol}, 1$ equiv). ${ }^{13} \mathrm{C}$ CPMAS NMR (101.6 MHz) $\delta$ : 132.1, 114.4, 73.1, 24.3, 21.9, 15.1 (P123), 6.5. ${ }^{29} \mathrm{Si}$ CPMAS NMR (79.5 MHz) $\delta:-66.7\left(T^{3}\right),-91.4\left(Q^{2}\right),-101.3\left(Q^{3}\right),-110.5$ $\left(Q^{4}\right)$. BET Surface Area: $640 \mathrm{~m}^{2} / \mathrm{g}$. BJH Desorption Average Pore 
Diameter: $9.5 \mathrm{~nm}$. TGA: Mass Loss $=1.2 \%$. SAXS: $\mathrm{d}(100)=11.2$ $\mathrm{nm}, \mathrm{a}=12.9 \mathrm{~nm}$.

General procedure for mesoporous silicas passivation. To non-passivated silica $(1 \mathrm{~g})$ in suspension in toluene $(75 \mathrm{~mL})$ were added triethylamine $(5.5 \mathrm{~mL})$ and trimethylsilylchloride $(4.1 \mathrm{~mL})$. The medium was heated for one night at $70{ }^{\circ} \mathrm{C}$ and then for one hour at $100{ }^{\circ} \mathrm{C}$ before being filtrated and washed once with toluene and once with ethanol. The recovered powder was stirred in ethanol during $4 \mathrm{~h}$ and then filtrated, washed twice with ethanol and twice with diethylether. After one night under vacuum at $80^{\circ} \mathrm{C}$, an orange/brown powder was recovered.

Experimental Procedures for EPR Analysis: EPR experiments were performed on an ELEXSYS Bruker instrument and the Bruker BVT 3000 set-up was used to control the temperature. The photolysis instrument (ORIEL version 66901 with an energy supplier version 68911) is equipped with a $300 \mathrm{X}$ UXL306 arc Xe lamp (200-800 nm) with an optical fiber (1 m, version 77620). In a $4 \mathrm{~mm}$ quartz-glass tube, $35 \mathrm{mg}$ of functionalized silica were degassed with three freeze-pumpthaw cycles with a $10^{-5}$ mbar vacuum pump. EPR spectra for direct observation of sulfur centered radical experiments were recorded with the following parameters: modulation amplitude $=1 \mathrm{G}$, receiver gain $=90 \mathrm{~dB}$, modulation frequency $=$ $100 \mathrm{kHz}$, power $=20 \mathrm{~mW}$, sweep width $=200 \mathrm{G}$, conversion time $=24 \mathrm{~ms}$, sweep time $=25 \mathrm{~s}$, number of scans $=2$.

\section{Acknowledgements}

The authors acknowledge the Agence Nationale de la Recherche for funding (ANR-12-JS07-005).

\section{Notes and references}

1 (a) D. Griller and K. U. Ingold, Acc. Chem. Res., 1976, 9, 13-19; (b) D. Griller and K. U. Ingold, Acc. Chem. Res., 1980, 13, 193-200.

2 O. Ouari, M. Hardy, H. Karoui and P. Tordo, Electron Paramagnetic Resonance 2011, 22, 1-40.

3 Q. Z. Ni, E. Daviso, T. V. Can, E. Markhasin, S. K. Jawla, T. M. Swager, R. J. Temkin, J. Herzfeld and R. G. Griffin, Acc. Chem. Res. 2013, 46, 1933-1941.

4 (a) I. Ratera and J. Veciana, Chem. Soc. Rev. 2012, 41, 303-349; (b) N. Domingo, E. Bellido and D. Ruiz-Molina, Chem. Soc. Rev. 2012, 41, 258-302; (c) M. Mas-Torrent, N. Crivillers, C. Rovira and J. Veciana, Chem. Rev. 2012, 112, 2506-2527.

5 R. G. Hicks, Org. Biomol. Chem., 2007, 5, 1321-1338.

6 For pioneering studies see: N. T. Kartel, Theor. Exp. Chem. 1980, 16, 109-113 and references therein.

7 (a) N. J. Turro, Acc. Chem. Res. 2000, 33, 637-646. (b) J. P. Da Dilva, S. Jockusch, J. M. G. Martinho, M. F. Ottaviani and N. J. Turro, Org. Lett., 2012, 12, 3062-3065 and references therein.

8 M. K. Kidder, A. L. Chaffee, M.-H. T. Nguyen and A. C. Buchanan, III, J. Org. Chem. 2011, 76, 6014-6023.

9 (a) A. Mehdi, C. Reye and R. Corriu, Chem. Soc. Rev., 2011, 40, 563-574. (b) J. E. Lofgreen and G. A. Ozin, Chem. Soc. Rev., 2014, 43, 911-933.
10 F. Vibert, S. R. A. Marque, E. Bloch, S. Queyroy, M. P. Bertrand, S. Gastaldi and E. Besson, J. Phys. Chem. C, 2015, 119, 5434-5439.

11 F. Vibert, S. R. A. Marque, E. Bloch, S. Queyroy, M. P. Bertrand, S. Gastaldi and E. Besson, Chem. Sci., 2014, 5, 4716-4723.

12 F. C. Thyrion, J. Phys. Chem. 1973, 77, 1478-1482.F

13 P. S. Engel, Chem. Rev. 1980, 80, 99-150.

14 F. Dénès, M. Pichowicz, G. Povie and P. Renaud, Chem. Rev. 2014, 114, 2587-2693.

15 The resulting materials were named $\mathbf{S B A}_{\mathbf{n}} \mathbf{- 1}$ in which 1 specifies the nature of the organic precursor and $n$ indicates the TEOS/radical precursor molar ratio determined after the characterization of the hybrid silicas.

16 (a) J. C. Walton, in Encyclopedia of Radicals in Chemistry, Biology and Materials, ed., C. Chatgilialoglu and A. Studer, Wiley, 2012, vol.1, ch. 7, 151-174. (b) U. Schmidt, Angew. Chem., Int. Ed., 1964, 3, 602-608. (c) W. Rundel and K. Scheffler, Angew. Chem., Int. Ed., 1965, 4, 243-244.

17 U. Schmidt and A. Müller, Angew. Chem., Int. Ed. 1963, 2, 216.

$18 \mathrm{~g}_{\text {iso }}=\left(2 \mathrm{~g}_{\perp}+\mathrm{g}_{/ /}\right) / 3$ see: $\mathrm{F}$. Gerson and W. Huber, in Electron Spin Resonance Spectroscopy of Organic Radicals, ed., F. Gerson and W. Huber, Wiley-VCH, 2003, pp 97-165.

19 D. J. Henry, M. B. Sullivan and L. Radom, J. Chem. Phys. 2003, 118, 4849-4860.

20 For a discussion of HAT in materials see: M. K. Kidder, P. F. Britt, Z. Zhang, S. Dai, E. W. Hagaman and A. C. Buchanan III, J. Am. Chem Soc. 2005, 127, 6353-6360.

21 For general reviews, see: (a) R. J. McMahon, Science, 2003, 299, 833-834. (b) D. Ley, D.s Gerbig and P. R. Schreiner, Org. Biomol. Chem., 2012, 10, 3781-3790.

22 a) S. Fujita, K. Kamazawa, S. Yamamoto, M.Tyagi, T. Araki, J. Sugiyama, N. Hasegawa and M. Kawasumi, J. Phys. Chem. C 2013, 117, 8727-8736. b) J. C. McKeen, Y. S. Yan and M. E. Davis, Chem. Mater. 2008, 20, 5122-5124. c) I. Alkorta and J. Elguero, Org. Biomol. Chem., 2006, 4, 3096-3101.

23 Y.-R. Luo, in Comprehensive Handbook of Chemical Bond Energies, CRC Press, 2007, ch. 3, 19-134.

24 E.T. Denisov, T.G. Denisova and T.S. Pokidova, in Handbook of Free Radical Initiators, John Wiley \& Sons, 2003, pp 441-478.

25 F. Rouquerol, J. Rouquerol, P. Llewellyn, G. Maurin, K. S. W. Sing, Adsorption by Powders and Porous Solids: Principles, Methodology and Applications $2^{\text {nd }}$ edition; Academic Press: London, 2013.

26 J. Schaefer and E. O. R. Stejskal, J. Am. Chem. Soc. 1976, 98, 1031-1032.

27 O. B. Peersen, X. Wu, I. Kustanovich and Smith, S. O. J. Magn. Reson. 1993, 104, 334-339.

28 R. L. Cook, C. H. Langford, R. Yamdagni and C. M. A. Preston, Anal. Chem. 1996, 68, 3979-3986.

29 G. Gerbaud, F. Ziarelli and S. Caldarelli, Chem. Phys. Lett. 2003, 377, 1-5. 